presented evidence that in an extract from Azotobacter the citric acid cycle was operating. As this extract was said to be translucent, and in view of the results of Schachman et al. ${ }^{2}$ with different species of bacteria, it is not unlikely that the largest particles were of the same order of magnitude as those found in Sup. 1.

It is of great interest that some of the reactions, which in animal tissues are known to depend upon the integrity of the mitochondria, can take place in a bacterial extract in which the largest element would have a diameter of about $150 \mathrm{~A}$., and therefore a volume of nearly one-millionth that of a mitochondrion.

However, as the activity of these bacterial extracts in the oxidation of some of the citric acid cycle intermediates is low compared with that of mitochondria, it is not inconceivable that when the cells are disrupted a cellular organization, necessary for optimum activity of the enzyme systems concerned, is disturbed.

I am indebted to Dr. P. Johnson for carrying out the experiments in the analytical ultracentrifuge and to Miss J. Moyle for her assistance in running the preparative Spinco centrifuge.

Molteno Institute,

A. Tissiéres

University of Cambridge. May 14.

1 Tissières, A., Nature, 169, 880 (1952).

'Schachman, H. K., Pardee, A. B., and Stanier, R. Y., Arch. Biochem. Biophys., 38, 245 (1952).
chachman, H. K.. Pardee, A. B.

${ }^{3}$ Siegel, A., Singer, S. J., and Wildman, S. G., Arch. Biochem. Biophys., 41, 278 (1952).

- Stone, R. W., and Wilson, P. W., J. Bact., 63, 605 (1952).

\section{Effects of Intraventricular Administration of Substance $P$}

The presence of substance $\mathrm{P}$ in the central nervous system was first shown by Euler and Gaddum" According to recent work on the distribution of this substance in the brain ${ }^{2,3}$, the largest amounts are found in the basal ganglia, the hypothalamus, the midbrain and the grey matter of the spinal cord. Nothing is known about the action and function of substance $\mathrm{P}$ in the nervous system. We have now observed tachypncea and hyperpnoea produced by substance $P$ injected into the third ventricle of the rabbit and the cat.

Substance $P$ was prepared and purified by the method of Euler ${ }^{4}$ and Pernow ${ }^{3}$. Cow intestine was cut into pieces, boiled in water at $p \mathrm{H} 4$ and the filtrate concentrated and precipitated with ammonium sulphate at 70 per cent saturation. The precipitate was purified by adsorption on aluminium oxide and elution with methanol. The activity of the preparation, tested on isolated guinea pig ileum, was 100-150 units per mgm. Substance $P$ was dissolved in Ringer's solution. The volume injected varied between 0.05 and $0.2 \mathrm{ml}$. A preparation of substance $\mathrm{P}$ inactivated with crystalline chymotrypsin was used as a control solution.

The animals were anæsthetized with urethane (rabbit) and 'Nembutal' (cat). Substance $\mathrm{P}$ was injected through a cannula inserted in the intersection of the coronal and sagittal sutures at right angles to the vertex of the skull. The position of the tip of the cannula in the third ventricle was checked after each experiment by injection of aniline blue. Respiration was measured quantitatively by using a body-plethysmograph.
Intraventricular injection of 5 units of substance $P$ produced, after a latent period of about five minutes, a successively increased rate of respiration of $30-50$ per cent with a maximal effect occurring after 10-15 min. With 20 units the effect was even more pronounced. There was also an increase in the amplitude of the respiratory movements. Usually the injections produced a slight, gradual rise in the blood pressure of about $10 \mathrm{~mm}$. mercury. 'These effects lasted from $20 \mathrm{~min}$. to more than two hours. A pronounced tachypnoea and increased respiratory amplitude were also observed in unanæsthetized rabbits after injection of 10 units of substance $P$. No effect was obtained with control injections of Ringer's solution or inactive solutions of substance P.

When injections were made into paraventricular tissue and the solution did not enter the ventricular system, no consistent or lasting effects upon the respiration were recorded.

Recently, the effects of intraventricular injections of different drugs have been studied by Feldberg and Sherwood ${ }^{5}$ Tachypnoea was observed after injections of histamine, 5 -hydroxy tryptamine, adenosine triphosphate, hexamethonium, $d$-tubocurarine and atropine.

Department of Physiology,

Faculty of Medicine,

Caroline Institute, Stockholm. April 15.

'Euler, U. S. v., and Gaddum, J. H., J. Physiol., 72, 74 (1931).

Amin, A. H. Crawford, T. B. B., and Gaddum, J. H.. XIXth Int. Physiol. Cong. (1953). Kopera. H., and Lazarini, W., Areh. Exp. Path. Pharmakol., 219, 214 (1953).

${ }^{3}$ Pernow, B., Acta Physiol. Scand. 29, Supp. 105, 1 (1953).

- Euler, U. S. v., Acta Physiol. Scand., 4, 373 (1942).

5 Feldberg, W. and Sherwood, S. L., J. Physiol., 123, 148 (1954).

\section{Development of Tolerance to Ganglion Blockade by Methonium Compounds}

THE clinical observation that tolerance follows the repeated administration of hexamethonium salts was reported by Smirk and others ${ }^{1}$; and Smirk ${ }^{2}$ has reported that the tolerance to hexamethonium salts was effective also in reducing the effects of other methonium salts. No reports concerning similar phenomena in animals have been found, and I have not found published observations as to the mechanism whereby tolerance occurs. This preliminary report is concerned with the mechanism by which tolerance is developed to the ganglion-blocking action of methonium salts.

Studies of the mydriatic effect of these agents in mice, and of blockade of the superior cervical sympathetic ganglia in the cat, indicate that tolerance of the ganglia to the effects of these substances follows their repeated administration to the whole animal. The local application of methonium compounds to isolated autonomic ganglia, however, did not give rise to any tolerance; but similar isolated preparations taken from animals which had previously been made tolerant by repeated doses of methonium salts were found to have become almost insensitive to these substances. The application of blood from tolerant animals and patients was found to confer tolerance on isolated ganglia from non-tolerant animals.

The superior cervical ganglia of bilaterally nephrectomized cats recovered from the effect of an 